\title{
Noninvasive Theranostic Imaging of HSVI-sr39TK- NTR/GCV-CB 954 Dual-Prodrug Therapy in Metastatic Lung Lesions of MDA-MB-23 I Triple Negative Breast Cancer in Mice
}

\author{
Thillai V. Sekar, Kira Foygel, Ohad Ilovich, and Ramasamy Paulmurugan ${ }^{\bowtie}$ \\ Molecular Imaging Program at Stanford, Bio-X Program, Stanford University School of Medicine, Stanford, California, USA.
}

$\square$ Corresponding author: Ramasamy Paulmurugan, Ph.D. Department of Radiology, Stanford University School of Medicine, 3155, Porter Drive, \#2236, Palo Alto, CA 94304. Phone: 650-725-6097; Fax: 650-721-6921 Email: paulmur8@stanford.edu.

(C) Ivyspring International Publisher. This is an open-access article distributed under the terms of the Creative Commons License (http:/ / creativecommons.org/ licenses/by-nc-nd/3.0/). Reproduction is permitted for personal, noncommercial use, provided that the article is in whole, unmodified, and properly cited.

Received: 2013.II.07; Accepted: 2014.01.20; Published: 2014.02.15

\begin{abstract}
Metastatic breast cancer is an obdurate cancer type that is not amenable to chemotherapy regimens currently used in clinic. There is a desperate need for alternative therapies to treat this resistant cancer type. Gene-Directed Enzyme Prodrug Therapy (GDEPT) is a superior gene therapy method when compared to chemotherapy and radiotherapy procedures, proven to be effective against many types of cancer in pre-clinical evaluations and clinical trials. Gene therapy that utilizes a single enzyme/prodrug combination targeting a single cellular mechanism needs significant overexpression of delivered therapeutic gene in order to achieve therapy response. Hence, to overcome this obstacle we recently developed a dual therapeutic reporter gene fusion that uses two different prodrugs, targeting two distinct cellular mechanisms in order to achieve effective therapy with a limited expression of delivered transgenes. In addition, imaging therapeutic reporter genes offers additional information that indirectly correlates gene delivery, expression, and functional effectiveness as a theranostic approach. In the present study, we evaluate the therapeutic potential of HSVI-sr39TK-NTR fusion dual suicide gene therapy system that we recently developed, in MDA-MB-23 I triple negative breast cancer lung-metastatic lesions in a mouse model. We compared the therapeutic potential of HSVI-sr39TK-NTR fusion with respective dual prodrugs GCV-CBI954 with HSVI-sr39TK/GCV and NTR/CBI954 single enzyme prodrug system in this highly resistant metastatic lesion of the lungs. In vitro optimization of dose and duration of exposure to GCV and CBI 954 was performed in MDA-MB-23I cells. Drug combinations of I $\mu \mathrm{g} / \mathrm{ml} \mathrm{GCV}$ and $10 \mu \mathrm{M} \mathrm{CBI} 954$ for 3 days was found to be optimal regimen for induction of significant cell death, as assessed by FACS analysis. In vivo therapeutic evaluation in animal models showed a complete ablation of lung metastatic nodules of MDA-MB-23I triple negative breast cancer cells following two consecutive doses of a combination of GCV $(40 \mathrm{mg} / \mathrm{kg})$ and CBI 954 (40 $\mathrm{mg} / \mathrm{kg}$ ) administered at 5 day intervals. In contrast, the respective treatment condition in animals expressing HSVI-sr39TK or NTR separately, showed minimal or no effect on tumor reduction as measured by bioluminescence (tumor mass) and $\left[{ }^{18} \mathrm{~F}\right]-\mathrm{FHBG}$ microPET (TK expression) imaging. These highlight the strong therapeutic effect of the dual fusion prodrug therapy and its use in theranostic imaging of tumor monitoring in living animals by multimodality molecular imaging.
\end{abstract}

Key words: Gene-Directed Enzyme Prodrug Therapy, theranostic imaging, tumor monitoring 


\section{Introduction}

Distal lung metastasis is often found in patients with advanced triple negative breast cancer, in which relapse is quite common when compared to estrogen receptor positive breast cancer [1]. Many consider lung metastasis as the terminal stage of different cancer types; it can be treated by neither conventional chemotherapy nor radio-therapeutic approaches due to the resistance of metastatic tumors. Breast cancer metastasis frequently involves many different organs, such as bone, lung, and brain; treatment options, like hormone therapy, are prevalent for receptor positive breast cancer sub-types, whereas palliative chemotherapy is the only option for receptor negative breast cancer. However, chemotherapy is not a promising therapeutic option for treatment of metastatic breast cancer. Gene therapy methods are identified as potential alternative therapeutic strategies for treating various cancers, including breast cancer metastasis.

Suicide gene therapy or Gene-Directed Enzyme Prodrug Therapy (GDEPT) involves an enzyme that selectively converts a nontoxic prodrug into an active cytotoxic drug and eventually kills the cells that harbor an active enzyme-coding gene. Suicide gene therapy combinations such as HSV1-sr39TK/GCV and NTR/CB1954 are well established and have reached clinical trials [2-5]. NTR enzyme converts the nontoxic prodrug CB1954 (5-(aziridin-1-yl)-2,4Dinitrobenzamide) into its active cytotoxic form (5-(aziridin-1-yl)-4-hydroxylamino-2-nitrobenzamide) , which creates DNA inter-strand crosslinks that are poorly repaired by cells [6], whereas HSV1-sr39TK phosphorylates GCV to GCV-monophosphate and subsequently into GCV-triphosphate by host cellular kinases, which in turn cause premature DNA chain termination and apoptosis [7]. Another GDEPT system, the cytosine deaminase/5-flurocytosine (CD/5-FC) has been widely investigated to treat various cancer types. CD/5-FC GDEPT involves 5 -flurocytosine as prodrug and 5-fluorouracil as final cytotoxic substance causing cell death by interfering with RNA processing or DNA synthesis. The $\mathrm{CD} / 5-\mathrm{FC}$ system exerts toxic effect only to cells expressing cytosine deaminase; therefore, it circumvents the systemic toxicity common to 5-FU. NTR/CB1954 and $\mathrm{CD} / 5-\mathrm{FC}$ systems have more bystander effect $[8$, 9] when compared to an HSV1-sr39TK/GCV system [10] due to the diffusive nature of their drug metabolites.

Because of the promising therapeutic value of GDEPT system, with minimal toxicity to non-target organs, several attempts have been made to increase the potency by combining it with other therapeutic systems. HSV1-sr39TK has induced pronounced cell death when co-expressed with caspase- 3 in ovarian carcinoma cells, and lead to anti-tumor immunity and tumor regression of subcutaneously implanted murine colon carcinoma $[11,12]$. NTR was also shown to have pronounced cell death against TRAMP cell lines when co-expressed with murine granulocyte macrophage colony-stimulating factor (mGM-CSF) [13]. Dual suicide gene therapy method is one of several approaches; enhanced the therapeutic effect compared to each of the respective GDEPT systems used independently. The expression of CD fused with uracil phosphoribosyltransferase (CD/UPRT) enhanced the conversion of 5-FC to 5-FU and then to active metabolites that inhibit DNA and RNA synthesis, showing enhanced therapeutic effect with significant bystander effect in adenoviral transduced colon cancer in vivo in mice [14, 15]. The expression of CD/HSV1-sr39TK fusion gene has shown significant enhancement in metabolic suicide and radio-sensitivity of glioma cells [16, 17]. Further, CD/HSV1-sr39TK bi-fusion showed enhanced cytotoxic effect when additionally fused with an adenovirus death protein (ADP) gene [18].

We recently reported the enhanced therapeutic effect of HSV1-sr39TK-NTR fusion with GCV-CB1954 prodrug combination, which target two different mechanisms, such as premature termination of DNA synthesis (HSV1-sr39TK/GCV) and inter-strand crosslinking by DNA alkylation (NTR/CB1954), in different cancer cells in vitro and in vivo in mice via molecular imaging $[19,20]$. In the present study, we show the therapeutic potential of GCV and CB1954 prodrug combination on triple negative metastatic breast cancer, specifically localized in the lungs, and compare its effect with HSV1-sr39TK/GCV and NTR/CB1954 prodrug GDEPT systems by theranostic imaging. Bioluminescence-based optical imaging and $\left[{ }^{18} \mathrm{~F}\right]-\mathrm{FHBG}$ microPET imaging were used to assess the therapeutic value of HSV1-sr39TK-NTR fusion in living animals.

\section{Materials and Methods}

\section{Plasmid vectors}

The cloning vectors used in this study, expressing bacterial nitroreductase gene (NTR2), mutant HSV1-thymidine kinase (HSV1-sr39TK), HSV1-sr39TK-NTR-fusion, and Fluc-EGFP fusion constructs were from our plasmid bank (Cellular Pathway Imaging Laboratory, Stanford). Plasmid extraction, DNA gel extraction, and genomic DNA extraction kits were purchased from Qiagen (Valencia, CA, USA).

\section{Cell culture}

Cell culture reagents, including culture media, fetal bovine serum (FBS), antibiotics (streptomycin 
and penicillin), and Lipofectamine 2000 transfection reagent were purchased from Invitrogen (Carlsbad, CA, USA). MDA-MB-231 cell line (ATCC HTB-26) was purchased from American Type Culture Collection (Manassas, VA, USA). Cells were tested for pathogens by VSC diagnostic lab, Stanford University. MDA-MB-231 cell line was cultured in Dulbecco's Modified Eagle's Medium supplemented with 10\% FBS and $1 \%$ penicillin-streptomycin.

\section{Stable cell lines}

To make MDA-MB-231 stable cell lines, modified pcDNA3.1 (PURO) vectors expressing HSV1-sr39TK, NTR, or HSV1-sr39TK-NTR fusion proteins and lentivirus expressing Fluc-EGFP fusion proteins were used. Initially we created MDA-MB-231 cells stably expressing HSV1-sr39TK, NTR, or HSV1-sr39TK-NTR fusion by puromycin antibiotic selection $(100 \mathrm{ng} / \mathrm{ml})$. Clones of cells expressing near equal level of each enzyme (assessed by RT-PCR) were used for further transduction with lentivirus expressing Fluc-EGFP to co-express both therapeutic gene and an imaging reporter gene. To control the level of Fluc-EGFP at near equal expression, cells were sorted by FACS in a similar window after transduction. MDA-MB-231 stable cells were maintained in puromycin stress throughout the study. Single colonies of stable cells were expanded and evaluated for the functionality of NTR enzyme by incubating with a CytoCy5S (red-shifted NTR substrate; GE Healthcare, Piscataway, NJ, USA) for the detection of emitted fluorescent signal and ${ }^{3} \mathrm{H}-\mathrm{PCV}$ uptake for HSV1-sr39TK. CytoCy5S (excitation $628 \mathrm{~nm} /$ emission $638 \mathrm{~nm}$ ) was dissolved in DMSO to a stock concentration of $2 \mathrm{mg} / \mathrm{ml}$. The substrate was used for all in vitro and in vivo experiments by diluting either in PBS or in cell culture medium. Cells containing luciferase and EGFP fusion constructs were screened by FACS. Clones expressing equivalent levels of NTR and HSV1-sr39TK (as measured by immunoblot analysis) were selected.

\section{Immunoblot analysis}

To determine the expression levels of TK in cells transfected with HSV1-sr39TK and HSV1-sr39TK-NTR, immunoblot analysis using anti-TK-antibody was performed. Cells were lysed in $100 \mu \mathrm{l}$ of RIPA lysis buffer (Pierce Biotechnology, Rockford, IL, USA), and $30 \mu \mathrm{g}$ of total protein from stable MDA-MB-231 cells expressing HSV1-sr39TK, NTR, and HSV1-sr39TK-NTR, in 1X Lamelli loading buffer with $\beta$-mercaptoethanol (Life Technologies, Grand island, NY, USA), were heated at $95^{\circ} \mathrm{C}$ for $5 \mathrm{~min}$, resolved using a 4-12\% SDS-polyacrylamide gel electrophoresis gradient gel (Invitrogen, Carlsbad, CA, USA), and electroblotted onto a $0.2 \mu \mathrm{m}$ pore size nitrocellulose membrane (Schleicher \& Schuell, Keene, NH, USA). The membrane was blocked with $5 \%$ non-fat dry milk in Tris-buffered saline containing $0.01 \%$ Tween-20 (TBS-T, pH 7.6) for $1 \mathrm{~h}$ and probed overnight at $4{ }^{\circ} \mathrm{C}$ on a rotating platform with the rabbit anti-human TK polyclonal antibody followed by incubation with peroxidase conjugated goat-anti rabbit IgG antibody (1:10,000 dilution, Rockland Immunochemicals, Gilbersville, PA, USA). The membranes were then re-probed with a mouse monoclonal antibody against human GAPDH (1:3,000, Novus Biologicals, Littleton, $\mathrm{CO})$ to control for protein loading. Immunoblots were developed using the LumiGlo enhanced chemiluminescence method (Cell Signaling, Boston, MA, USA), following manufacturer's instructions using IVIS-Lumina imaging system (Caliper Life Sciences, MA, USA).

\section{${ }^{3} \mathrm{H}-$ Penciclovir (PCV) uptake assay}

Quantitative evaluation of the functional effect of TK in cells stably transfected with HSV1-sr39TK, and HSV1-sr39TK-NTR fusions was performed by ${ }^{3} \mathrm{H}-$ Penciclovir uptake assay as described in Sekar et al., 2012 [20]. Briefly, MDA-MB-231 cells stably expressing HSV1-sr39TK, NTR, and HSV1-sr39TK-NTR along with control cells were plated $\left(2 \times 10^{5}\right.$ cells per well) in 12-well plates. Twenty-four hours after plating, cells were treated with $0.5 \mu \mathrm{Ci}$ of $8-{ }^{3} \mathrm{H}$-Penciclovir (specific activity $14.9 \mathrm{Ci} \mathrm{mmol}^{-1}$; Moravek Biochemicals, La Brea, CA, USA). After $3 \mathrm{~h}$ of incubation at $37^{\circ} \mathrm{C}$ with $5 \% \mathrm{CO}_{2}$, cells were washed twice with ice-cold PBS and lysed in $0.5 \mathrm{ml}$ of $0.1 \mathrm{~N} \mathrm{NaOH}$, analyzed by scintillation counter by adding $10 \mathrm{ml}$ of cytoscint scintillation cocktail solution (Fisher Scientific, USA). The radioactivity readings were normalized to protein concentrations measured from a $20 \mu \mathrm{l}$ aliquot of cell lysates.

\section{Fluorescence-activated cell sorting (FACS) analysis for CytoCy5S uptake in cells expressing NTR}

MDA-MB-231 cells were seeded in $10 \mathrm{~cm}$ culture plates to $60-70 \%$ confluency and transfected with plasmids expressing HSV1-TK, NTR, and HSV1-sr39TK-NTR after overnight incubation. After $24 \mathrm{~h}$ of further incubation, cells were treated with CytoCy5S (100 ng ml-1) dye for $1 \mathrm{~h}$ and subjected to FACS analysis. Cells expressing NTR and HSV1-sr39TK-NTR were sorted using CytoCy5S reduction signal and maintained for further studies.

\section{Fluorescence-activated cell sorter (FACS) for PI based apoptosis analysis}

Stable MDA-MB-231 cells were seeded in 12-well culture plates and grown to $30-40 \%$ confluency, fol- 
lowed by $72 \mathrm{~h}$ treatment with various concentrations of GCV and CB1954 in various combinations $(1 \mu \mathrm{g} / \mathrm{ml}$ GCV, $5 \mu \mathrm{M}$ CB1954, $10 \mu \mathrm{M}$ CB1954, $1 \mu \mathrm{g}$ GCV $+5 \mu \mathrm{M}$ CB1954, $1 \mu \mathrm{g}$ GCV+10 $\mu \mathrm{M}$ CB1954); untreated MDA-MB-231 cells were used as control. For a time course study, $1 \mu \mathrm{g}$ of GCV $+10 \mu \mathrm{M}$ CB1954 was administered to cells that were observed for 5 days. Cells were trypsinized, washed, and analyzed for dead or apoptotic cells by staining with propidium iodide (15 $\mathrm{nM}$ ) for $15 \mathrm{~min}$, followed by flow cytometry (FACS Aria III, BD Biosciences, San Jose, CA, USA) at the Stanford FACS Facility. Data were analyzed by FlowJo FACS analysis software (Tree Star, Ashland, OR, USA). GCV and CB1954 were purchased from Sigma-Aldrich (St Louis, MO, USA).

\section{Tumor xenograft studies and imaging}

The Institute Animal Research Committee at Stanford approved all animal handling. All animals (CD1, nude) were purchased from Charles River Laboratories (Wilmington, MA, USA). The mice ( $\mathrm{N}=5$ per treatment group) were intravenously injected with $1 \times 10^{5}$ MDA-MB-231 triple-negative breast cancer cells (200 $\mu 1$ in 2 min injections), stably co-expressing HSV1-TK-NTR and Fluc-EGFP fusion proteins, and allowed to establish metastatic tumors primarily in lungs. Animals were optically imaged by IVIS spectrum (IVIS-Spectrum Imaging System, Caliper Life Sciences, MA), followed by D-luciferin substrate injection every alternative day until desirable metastatic tumor was detected. Mice were divided into three groups, and treated with (1) GCV (40 mg/kg body weight), (2) CB1954 (40 mg/ $\mathrm{kg}$ body weight) and (3) CB1954 (40 mg/ $\mathrm{kg}$ ) and GCV (40 mg/ $\mathrm{kg}$ body weight), with two doses of prodrugs administered spaced 5 days apart. Drugs were given intraperitoneally by mixing $10 \%$ of PEG400 in $250 \mu$ l volume with sterile physiological saline. All animals were imaged before drug treatment to obtain a baseline image by optical CCD camera. The animals were imaged by an optical imaging camera on a daily basis following treatment initiation, and both the imaging and treatment continued for 10 days before the metastatic tumor grew to a level lethal to animal.

\section{Positron Emission Tomography imaging and image analysis}

Positron Emission Tomography/Computed tomography (PET/CT) imaging was performed prior to, and 9 days post, initiation of therapy with $\left[{ }^{18} \mathrm{~F}\right]-\mathrm{FHBG}$. $\left.{ }^{[18} \mathrm{F}\right]-\mathrm{FHBG}$, a PET reporter probe for imaging the PET reporter genes, HSV1-TK and its mutant HSV1-sr39tk, is currently undergoing clinical evaluation [21]. In each imaging session, mice were anesthetized with $2 \%$ isoflurane in oxygen at $2 \mathrm{~L} / \mathrm{min}$, and $7.4-8.9 \mathrm{MBq}$ of $\left.{ }^{18} \mathrm{~F}\right]-\mathrm{FHBG}$ in $200 \mu \mathrm{l}$ was intravenously injected via tail vein. Five-minute static PET scans were performed 3 hours after injection by using a micro-PET/CT (1.4-mm resolution, Inveon; Siemens, Malvern, PA, USA) preceded by CT scans for anatomic reference. Volumes of interest (VOIs) were drawn using the image analysis software IRW (Siemens). VOIs were drawn for lung tumors based on the CT scan and centered on the activity profile peak. Data $(\% \mathrm{ID} / \mathrm{g})$ was corrected for partial volume effect and spillover [22] using calibration factors obtained from scanning a cylinder containing phantoms of different sizes.

\section{TUNEL assay}

The tumor xenografts of MDA-MB-231 cells expressing various combinations of therapeutic reporter genes (NTR, HSV1-sr39TK HSV1-sr39TK-NTR), after treatment or co-treatment with GCV and CB1954, were used for assessing the prodrug-induced therapeutic effects by visualizing apoptotic cells. For this, a portion of the tumor was frozen in OCT (TissueTek) and sectioned to $10 \mu \mathrm{m}$ by a Cryomicrotome (Leica CM1850, Wetzlar, Germany). A terminal deoxynucleotidyltransferase (TdT) nick-end labeling (TUNEL) assay was performed with a Trevigen TACS 2 TdT-DAB (diaminobenzidine) in situ Apoptosis Detection Kit (TREVIGEN, Gaithersburg, MD, USA) according to the manufacturer's instructions. After staining, the slides were scanned in a Nanozoomer 2.0RS (Hamamatsu, Japan) digital scanner and assessed for diaminobenzidine staining of apoptotic cells using Nanozoomer Digital Pathology software.

\section{Histology}

Tumor xenografts were frozen in OCT cryoprotective fixing medium, sliced at $5 \mu \mathrm{m}$ thickness by Leica cryomicrotome. Sections were stained by undiluted hematoxylene (Sigma-Aldrich, USA) for two minutes, rinsed in running water, and differentiated in $1 \% \mathrm{HCl}$ acid/alcohol for $30 \mathrm{sec}$. They were then washed and immersed into Bluing solution (Fisher, USA) for $1 \mathrm{~min}$, washed in running water and rinsed in 10 dips of $95 \%$ alcohol. After this, slides were counterstained in eosin by dipping into 1:5 ethanol-diluted Eosin solution (Fisher) for a total of less than $30 \mathrm{sec}$, and dehydrated through 95\% alcohol, absolute alcohol, and xylene for 5 minutes each. Slides were mounted with xylene based mounting medium (Permount, Sigma) and imaged by Nanozoomer (Hamamatsu, Japan) digital slide scanner.

\section{Results}

Functional characterization of MDA-MB-23 I stable cells expressing NTR and HSVI-sr39TK- 
NTR fusion proteins by CytoCy5S fluorescent assay

In order to prove the functional efficacy of MDA-MB-231 cell lines stably expressing the NTR gene (NTR and HSV1-sr39TK-NTR), actively growing stable cell lines plated on top of a sterile cover slip in six well plates were exposed to an NTR substrate (1 $\mathrm{ng} / \mathrm{ml})$, the Cytocy5S dye for $3 \mathrm{~h}$ and observed for Cy5 signal under fluorescent microscope. Cytocy5S is the substrate of nitroreductase enzyme, which catalyzes the conversion of Cytocy5S into the reduced form of Cytocy5S. Reduced CytoCy5S, a red-shifted fluorescent dye, is retained by mammalian cells and further acts as non-toxic imaging agent of the NTR enzyme. MDA-MB-231 cells expressing NTR and HSV1-TK-NTR fusion proteins showed fluorescent signals with Tx-Red filters while controls and cells expressing HSV1-TK-alone showed no fluorescent signals (Figure 1A). Furthermore, MDA-MB-231 stable cells plated in six well plates exposed to $1 \mathrm{ng} / \mathrm{ml}$ of CytoCy5S for 3 hrs were subjected to FACS analysis to ascertain the functionality of NTR and HSV1-sr39TK-NTR fusion proteins. NTR and HSV1-sr39TK-NTR expressing MDA-MB-231 stable cells showed higher Cy5 signal due to reduced $\mathrm{Cy}-$ toCy5S accumulation. In contrast, the control and HSV1-sr39TK expressing MDA-MB-231 cells did not show any fluorescent signals. MDA-MB-231 HSV1-sr39TK-NTR stable cells showed a log order higher signal compared to NTR expressing MDA-MB-231 stable cells (Figure 1B).

\section{Functional characterization of MDA-MB-23 I stable cells expressing HSVI-sr39TK and HSVI-sr39TK-NTR fusion proteins by ${ }^{3} \mathrm{H}-\mathrm{PCV}$ uptake assay}

We have performed ${ }^{3} \mathrm{H}-\mathrm{PCV}$ uptake assay to measure the functional efficiency of HSV1-sr39TK and HSV1-sr39TK-NTR expressing MDA-MB-231 cells. The HSV-sr39TK enzyme catalyzes the conversion of penciclovir (PCV) into penciclovir monophosphate, subsequently cellular TK enzymes phosphorylate monophosphate form of penciclovir into penciclovir triphosphate, which HSV1-sr39TK expressing mammalian cells use for DNA synthesis. The accumulation of penciclovir indirectly implies the functional efficiency of the HSV1-sr39TK enzyme expressed in cells.
MDA-MB-231 stable cells expressing HSV1-sr39TK-NTR fusion protein showed $\sim 80$ fold higher ${ }^{3} \mathrm{H}-\mathrm{PCV}$ uptake compared to control MDA-MB-231 cells $(17511 \pm 1880 \mathrm{CPM} /$ total Protein in HSV1-sr39TK-NTR cells vs $220 \pm 21 \mathrm{CPM} /$ total Protein in control cells), and MDA-MB-231 stable cells expressing HSV-sr39TK showed 1.2 fold lower ${ }^{3} \mathrm{H}-\mathrm{PCV}$ uptake than HSV1-sr39TK-NTR cells (Figure 1C).Functional characterization for the expression level of HSV1-sr39TK, NTR, and HSV1-sr39TK-NTR fusion proteins in MDA-MB-231 stable cells by qRT-PCR and immunoblot analysis

Besides the functional characterization of MDA-MB-231 stable cells with fluorescent microscopy, FACS, and ${ }^{3} \mathrm{H}-\mathrm{PCV}$ uptake assay, we did qRT-PCR and immunoblot analysis to show the level of HSV1-sr39TK and HSV1-sr39TK-NTR fusion proteins expressions in different MDA-MB-231 stable cells. To confirm the mRNA expression level of HSV1-TK, NTR and HSV1-TK-NTR fusion proteins, we performed quantitative PCR analysis. Amplicon sizes of HSV1- sr39TK and NTR specific primers were confirmed and mRNA expression of NTR in MDA-MB-231 stable cells expressing NTR and HSV1-sr39TK-NTR fusion proteins and TK in HSV1-sr39TK and HSV1-sr39TK-NTR expressing MDA-MB-231 cells were found to be similar (Figure 1D). PCR primers designed to amplify specifically NTR and HSV1-sr39TK were used for qRT-PCR analysis (Table 1). HSV1-sr39TK specific antibody detected protein bands of 42 and $65 \mathrm{kDa}$ in MDA-MB-231 stable cells expressing HSV1-sr39TK and HSV1-sr39TK-NTR fusion proteins respectively. The results also further confirmed the near equal level of protein expression in HSV1-sr39TK and HSV1-sr39TK-NTR expressing MDA-MB-231 cells. Control MDA-MB-231 cells, and NTR expressing MDA-MB-231 cells did not show any protein bands of respective sizes (Figure 1E).

Table I. Primers for RT-PCR.

\begin{tabular}{lll}
\hline Primers & Sequence $\left(5^{\prime} \mathbf{3}^{\prime}\right)$ & $\begin{array}{l}\text { Primer location } \\
\text { in genes }\end{array}$ \\
\hline NTR F & TGGTTGTTGACCAGGAAG & $290-307$ \\
NTR R & GCGTCAAAACCTTCGATG & $506-489$ \\
HSV1-TK F & TACCCGAGCCGATGACTTAC & $242-261$ \\
HSV1-TK R & CCGATTAGAGGAGCCAGAAC & $431-412$ \\
\hline
\end{tabular}



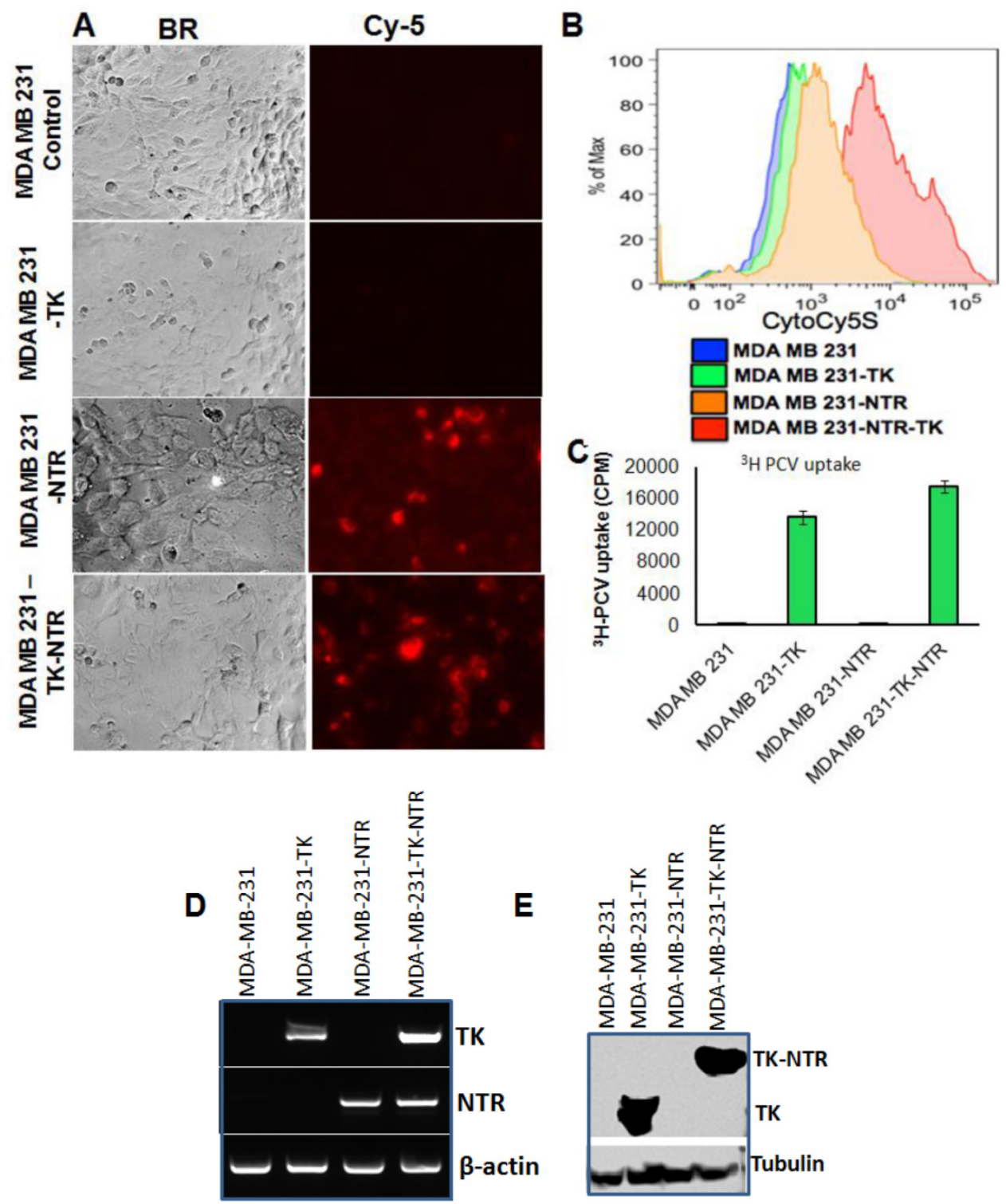

Figure I. A. Microscopic images of MDA-MB-23I stable cells expressing HSVI-sr39TK, NTR and HSVI-sr39TK-NTR fusion $3 \mathrm{~h}$ after exposure to CytoCy5S, a quenched fluorescent substrate of NTR. Left panel shows bright field images and right panel shows the fluorescent microscopic images of stable cells entrapping reduced CytoCy5S dye. B. FACS histogram overlay of MDA-MB-23I HSVI-sr39TK, NTR and HSVI-sr39TK-NTR stable cells treated with CytoCy5S dye. C. Graph shows ${ }^{3} \mathrm{H}-\mathrm{PCV}$ uptake of MDA-MB-23I stable cells expressing HSV-sr39TK, NTR and HSV-sr39TK-NTR fusion proteins. D. Quantitative RT-PCR analysis of MDA-MB-23 I stable cells expressing HSVI-sr39TK, NTR and HSVI-sr39TK-NTR fusion shows nearly equal level of mRNA expression for stably transfected HSVI-sr39TK, NTR, HSVI-sr39TK-NTR fusion. E. Immunoblot analysis shows the expression of HSVI-sr39TK and HSVI-sr39TK-NTR fusion protein stained with TK specific antibody.

\section{GCV and CB I 954 dose dependent cell death in MDA-MB-23 I cells stably expressing HSVI- sr39TK, NTR, or HSVI-sr39TK-NTR fusion protein}

Different concentration and combinations of GCV and CD1954 were evaluated for optimization of their cytotoxic effect versus MDA-MB-231 cells stably expressing HSV1-sr39TK, NTR, and HSV1-sr39TKNTR fusion proteins. We chose various concentrations of GCV and CB1954 and their combinations $(1 \mu \mathrm{g} / \mathrm{ml})$, CB1954 (1, 5 and $10 \mu \mathrm{M})$, and combinations (GCV $1 \mu \mathrm{g} / \mathrm{ml}+\mathrm{CB} 19541 \mu \mathrm{M}, \mathrm{GCV} 1 \mu \mathrm{g} / \mathrm{ml}+\mathrm{CB} 19545$ $\mu \mathrm{M}$, and GCV $1 \mu \mathrm{g} / \mathrm{ml}+\mathrm{CB} 195410 \mu \mathrm{M})$. MDA-MB-231 cells were harvested $72 \mathrm{~h}$ post-treatment, stained with propidium iodide (PI) and subjected to FACS analysis. MDA-MB-231 cells treated with similar concentrations of GCV and CB1954 were used as control. The results showed no cell death from MDA-MB-231 control cells after being treated with various concentrations of prodrugs used for the study. HSV1-sr39TK expressing cells showed 23.6, 23.4, 24.1, and $26.5 \%$ cell death with the treatment of GCV $1 \mu \mathrm{g} / \mathrm{ml}, \mathrm{GCV} 1 \mu \mathrm{g} / \mathrm{ml}+\mathrm{CB} 19541 \mu \mathrm{M}$, $\mathrm{GCV} 1 \mu \mathrm{g} / \mathrm{ml}+\mathrm{CB} 19545 \mu \mathrm{M}$, and GCV $1 \mu \mathrm{g} / \mathrm{ml}+$ CB1954 $10 \mu \mathrm{M}$ concentrations respectively. 
MDA-MB-231 cells expressing NTR induced 7.78, $13.8,14.7,8.57,12.9$, and $13.5 \%$ cell death with CB1954 $1 \mu \mathrm{M}, \mathrm{CB} 19545 \mu \mathrm{M}, \mathrm{CB} 195410 \mu \mathrm{M}, \mathrm{GCV} 1 \mu \mathrm{g} / \mathrm{ml}+$ CB1954 $1 \mu \mathrm{M}, \mathrm{GCV} 1 \mu \mathrm{g} / \mathrm{ml}+\mathrm{CB} 19545 \mu \mathrm{M}$, and GCV $1 \mu \mathrm{g} / \mathrm{ml}+\mathrm{CB} 195410 \mu \mathrm{M}$ concentrations respectively. MDA-MB-231 cells expressing HSV1-sr39TK-NTR fusion showed 28.8, 8.62, 9.91, 12.4, 24.2, 53.5, and $71.4 \%$ cell death when treated with GCV $1 \mu \mathrm{M}$, CB1954 $1 \mu \mathrm{M}$, CB1954 $5 \mu \mathrm{M}, \mathrm{CB} 195410 \mu \mathrm{M}, \mathrm{GCV}$
$1 \mu \mathrm{g} / \mathrm{ml}+\mathrm{CB} 19541 \mu \mathrm{M}, \mathrm{GCV} 1 \mu \mathrm{g} / \mathrm{ml}+\mathrm{CB} 19545 \mu \mathrm{M}$, and GCV $1 \mu \mathrm{g} / \mathrm{ml}+\mathrm{CB} 195410 \mu \mathrm{M}$ concentrations respectively (Figure 2A). HSV1-sr39TK-NTR expressing MDA-MB-231 cells showed 2.7 and 5.2 fold more cell death with the co-treatment of GCV and CB1954 (GCV $1 \mu \mathrm{g} / \mathrm{ml}+\mathrm{CB} 195410 \mu \mathrm{M}$ concentration) when compared with HSV1-TK and NTR alone expressing cells respectively.
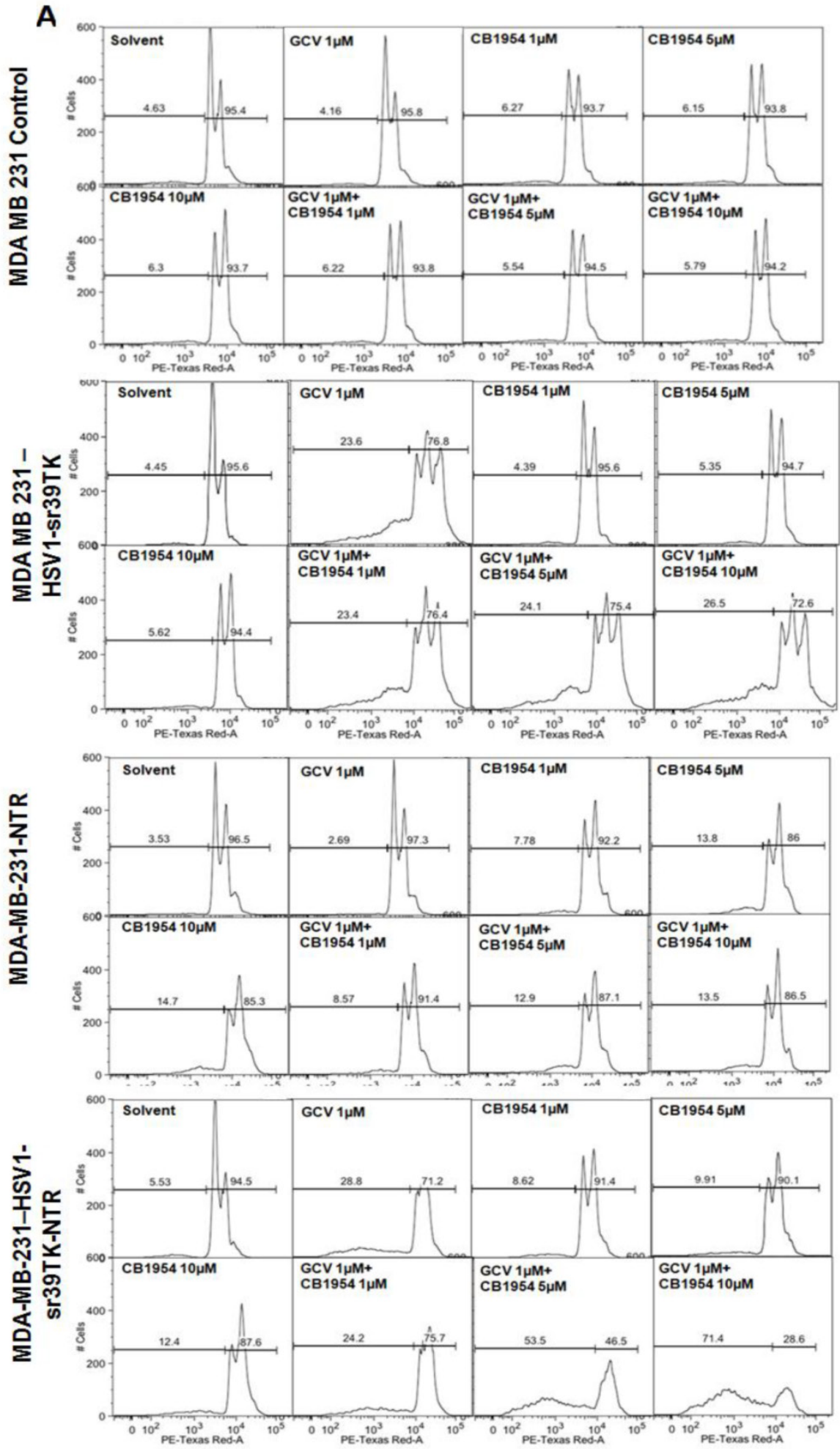


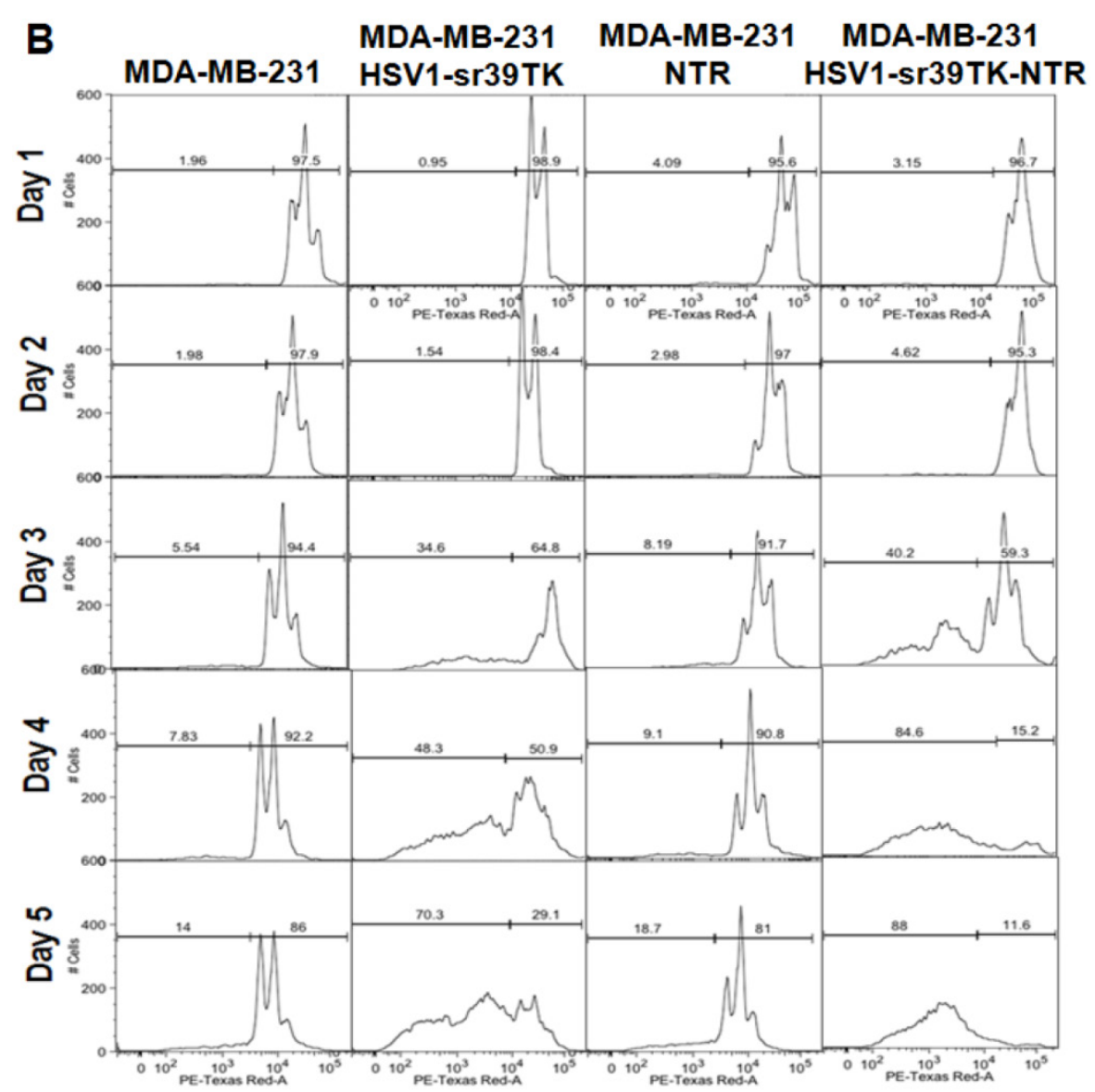

Figure 2. A. FACS analysis of MDA-MB-23I stable cells expressing HSVI-sr39TK, NTR and HSVI-sr39TK-NTR fusion proteins treated with various concentrations and combinations of GCV, CBI954 for 3 days and stained with propidium iodide (PI). Percentage of live and dead cells are labeled. B. FACS analysis of MDA-MB-23I HSVI-sr39TK, NTR and HSVI-sr39TK-NTR stable cells treated with a combination of I $\mu g$ GCV and I0 $\mu$ M CBI 954 and assayed for five consecutive days. Percentage of live and dead cells are labeled in each sample panel.

The effect of GCV and CB I 954 combination treatment in MDA-MB-23 I cells stably expressing HSVI-sr39TK, NTR, and HSVI-sr39TK-NTR fusion proteins over time

The GCV and CB1954 combination with a concentration of GCV $1 \mu \mathrm{g} / \mathrm{ml}+\mathrm{CB} 195410 \mu \mathrm{M}$ for $72 \mathrm{hrs}$ induced maximum cell death ( 72\%) in MDA-MB-231 cells expressing HSV1-sr39TK-NTR fusion protein. This particular concentration of drugs was further evaluated for its time dependent cell killing effect in MDA-MB-231 cells stably expressing HSV1-sr39TK, NTR, or HSV1-sr39TK-NTR fusion protein for over 5 days. The stable cells seeded in 12 well culture plates to a confluency of $30 \%\left(5 \times 10^{4} /\right.$ well $)$ were exposed to GCV $1 \mu \mathrm{g} / \mathrm{ml}+$ CB1954 $10 \mu \mathrm{M} 24$ hours after cell plating. Cells were harvested every day and fixed with ethanol consecutively for 5 days for FACS analysis. PI stained cells were FACS analyzed, and the data showed significant cell death from 3 days onwards of post-drug treatment. MDA-MB-231 control cells and MDA-MB-231 cells stably expressing HSV1-sr39TK, NTR, and HSV1-sr39TK-NTR fusion proteins induced $5.54,34.6,8.19$, and $40.2 \%$ of cell death, respectively, 3 days post-treatment and 14, $70.3,18.7$, and $88 \%$ cell death 5 days post-treatment (Figure 2B).

Evaluation of the potential of HSVI-TK-NTRfusion in dual prodrug cancer therapy in lung metastatic lesions of MDA-MB-23 I triple negative breast cancer in mice by optical bioluminescence imaging

MDA-MB-231 cells stably co-expressing HSV1-sr39TK-NTR and Fluc-EGFP fusion proteins were used to develop a lung-metastatic, nude mice model. MDA-MB-231 stable cells $\left(1 \times 10^{5}\right)$ in $200 \mu \mathrm{l}$ were injected into nude mice intravenously through the tail vein and allowed to establish metastatic tumors. Implanted mice were monitored for metastatic tumor formation by Fluc-based optical bioluminescence imaging in either position (prone and supine) of the animals. Nude mice with metastatic tumors were divided into four groups for prodrug combination treatment (GCV and CB1954). The first group received equal volumes of solvents; the second group received 
$40 \mathrm{mg} / \mathrm{kg}$ of GCV, the third group, a combination of GCV $(40 \mathrm{mg} / \mathrm{kg})$ and CB1954 (40 mg/ kg), and the fourth group with $40 \mathrm{mg} / \mathrm{kg}$ of CB1954. Each group of animals received two doses of drugs at 5-day intervals. Fluc-based optical imaging was performed daily, following the first administration of drugs. Figure 3 shows the optical imaging of control group, GCV, CB1954, and combination of GCV and CB1954 (Figure 3A-D) treated animals up to day 9, post-drug treatment. Fluc signal from the GCV + CB1954 combined group completely disappeared on day 9 (Figure B (top) and D), and the GCV-treated animal group showed significant amounts of Fluc signal reduction from day 7 onwards, indirectly showing metastatic tumor regression (Figure $\mathbf{A}$ (lower) and $\mathrm{C}$ ). The CB1954-treated animal group did not show any tumor regression (Figure 3B (lower)). The control group showed significant increase by day 9 (Figure $3 \mathbf{A}$ (top)).
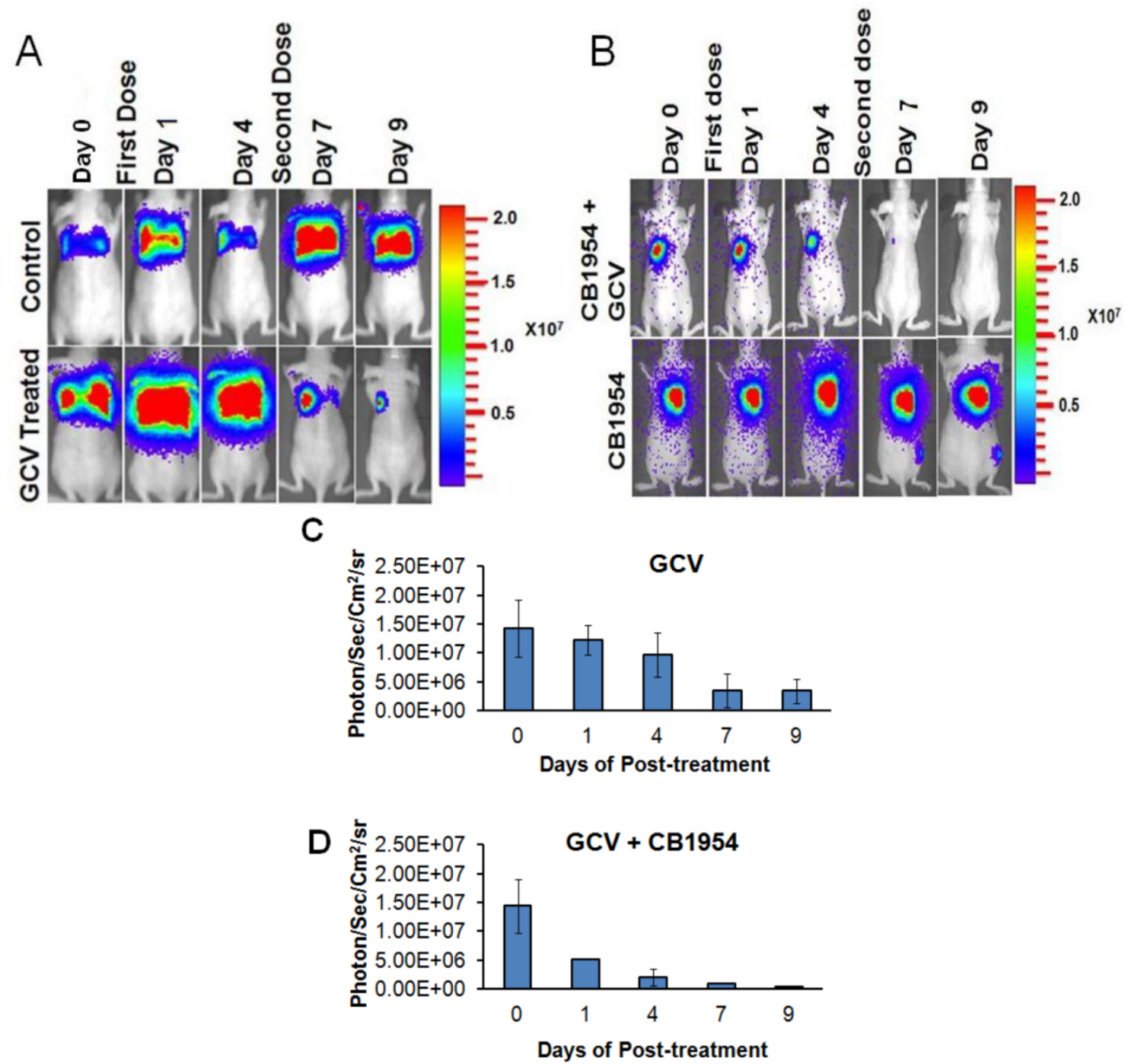

Figure 3. Optical imaging of metastatic animal model of MDA-MB-23I triple negative breast cancer cells stably expressing HSVI-sr39TK-NTR and treated with a combination of CBI954 and GCV. A. Upper panel shows the control nude mice treated with vehicle control imaged over time with D-Luciferin substrate and lower panel shows Fluc imaging of animal group treated with GCV alone. B. Upper panel shows the TK-NTR in MDA-MB-23I metastatic tumor in nude mice treated with CBI954 and GCV combination and imaged over time with D-Luciferin substrate. Lower panel shows the optical images of animal treated with CBI954 alone. Metastatic animal models were divided in to two groups ( $n=3$ to 5 ) and treated with 2 doses of CBI954 + GCV combined and CBI 954 alone at different time point. Imaging was done with cooled CCD camera (IVIS Spectrum) daily over a period of 9 days. Graph shows the Fluc signal level of animal group in different days treated with C, GCV and D, GCV + 1954, The animals treated with vehicle control and CBI954 alone increase in tumor size. 


\section{Theranostic PET/CT Imaging shows efficient therapeutic potential by GCV/CB I 954 prodrug therapy in MDA-MB-23 I metastatic tumor expressing HSVI-sr39TK-NTR fusion in mice}

We implanted MDA-MB-231 cells stably co-expressing HSV1-sr39TK-NTR and Fluc-EGFP fusions into nude mice, as described earlier, in order to induce lung-metastatic breast cancer. Animals were subjected to optical and microPET/CT imaging prior to GCV + CB1954 treatment and 9 days post-drug treatment. Optical imaging was done on days $0,1,4,7$, and 9 , and the imaging signals were compared. Fluc signal was significantly lower in animal groups treated with GCV + CB1954 on day 4, and drastically dropped down by day 9 (Figure 4A, B \& D), while Fluc signal in the control animal group was constantly increasing over time (Figure 4A, B \& C). MicroPET/CT imaging of animals before treatment with the GCV+CB1954 combination by [ $\left.{ }^{18} \mathrm{~F}\right]-\mathrm{FHBG}$, the substrate for HSV1-sr39TK, showed clear metastatic nodules in the lungs of the mice, which was similar to what we observed in the control group. In contrast, at nine days post treatment, the animals which received two doses of the GCV + CB1954 combination showed complete clearance of tumor nodules (Note: The treatment was not only effective for the removal of lung nodules, it also effectively removed a tumor found in the abdominal cavity in one animal). In the control group, even though microPET imaging did not show clear tumor nodules because of its low sensitivity, the optical imaging clearly confirmed for the presence of tumors before treatment. Figure 4A shows, at 3 hours post-injection, typical accumulation of $\left[{ }^{18} \mathrm{~F}\right]-\mathrm{FHBG}$ in the gastrointestinal tract, gall bladder, and bladder $[23,24]$ in all mice, but did not interfere with discerning VOIs in the lungs of mice. Tumors were visible in $6 / 7$ animals prior to therapy initiation and in 5/6 animals that survived therapy. Uptake in tumors of treated animals decreased from $2.86 \pm 1.15(\mathrm{n}=3)$ to $0.99 \pm 1.21(\mathrm{n}=3) \% \mathrm{ID} / \mathrm{g}(\mathrm{p}=0.05)$. Uptake in tumors of untreated animals increased from $1.18 \pm 0.54(\mathrm{n}=3)$ to $4.24 \pm 0.87(\mathrm{n}=3)(\mathrm{p}<0.001)($ Table 2). Tumors in treated animals not only showed decrease in $\left.{ }^{[18} \mathrm{F}\right]-\mathrm{FHBG}$ uptake, but also underwent shrinkage from approximately $3.5 \mathrm{~mm}$ to $<0.7 \mathrm{~mm}$ in diameter, while in untreated animals the tumor had grown from $2 \mathrm{~mm}$ to $3 \mathrm{~mm}$ (Figure 4E).
Table 2. [ $\left.{ }^{18} \mathrm{~F}\right]-\mathrm{FHBG}$ uptake in lung tumors pre-and post-treatment with $\mathrm{CB} 1954+\mathrm{GCV}$.

\begin{tabular}{lll}
\hline Animal Group & $\begin{array}{l}\text { Pre-treatment tumor } \\
\text { uptake }(\% \mathrm{ID} / \mathrm{g})\end{array}$ & $\begin{array}{l}\text { Post-treatment tumor } \\
\text { uptake }(\% \mathrm{ID} / \mathrm{g})\end{array}$ \\
\hline Vehicle Treatment & $1.18 \pm 0.54$ & $4.25 \pm 0.87$ \\
GCV + CB1954 & $2.86 \pm 1.15$ & $0.99 \pm 1.21$ \\
Treatment & & \\
\hline
\end{tabular}

\section{Histology and TUNEL staining}

Lung metastatic samples from different groups were fixed in OCT fixative and sliced to a thickness of $5 \mu \mathrm{M}$ and subjected to H\&E and TUNEL staining to see the actual status of the metastatic tumor before and after GCV + CB1954 treatment. Lung-metastatic breast tumors completely disappeared in tissue slices from the drug-treated animal group, and tumors in the CB1954-alone treated animal group and untreated control groups were intact without any changes (Figure 5A \& B).

\section{Discussion}

Breast cancer metastasis is an advanced stage of breast cancer that differs from primary breast cancer in many aspects, like steroid receptor status, especially estrogen receptor (ER), progesterone receptor (PR), and Her2 positivity [25]. Drug resistance of metastatic breast cancer has been attributed to the change in receptor status, altered expression of MRP1, $\mathrm{BCRP}$, and adenosine triphosphate-binding cassette (ABC) superfamily of transporters, PTEN and Bcl-2, and loss of DNA repair mechanisms [26]. Because of its heterogenic nature and drug resistance, metastatic breast cancer sub-types do not respond well to currently available chemotherapeutic regimens. Furthermore, treatment approaches and drug combinations need to be tailored to the particular metastatic phenotype; therefore, alternative treatment options targeting metastatic breast cancer, irrespective of its sub-type, is highly desirable [27]. GDEPT systems have been recognized as potential therapeutic methods to treat various cancer types because of their specificity and intrinsic bystander effect. Although a number of GDEPT systems have been developed, very few of them show promising therapeutic value. HSV1-TK/GCV, CD/5-FC, and NTR/CB1954 are well-established GDEPT systems being explored in clinical trials to use in real-time clinical settings. 


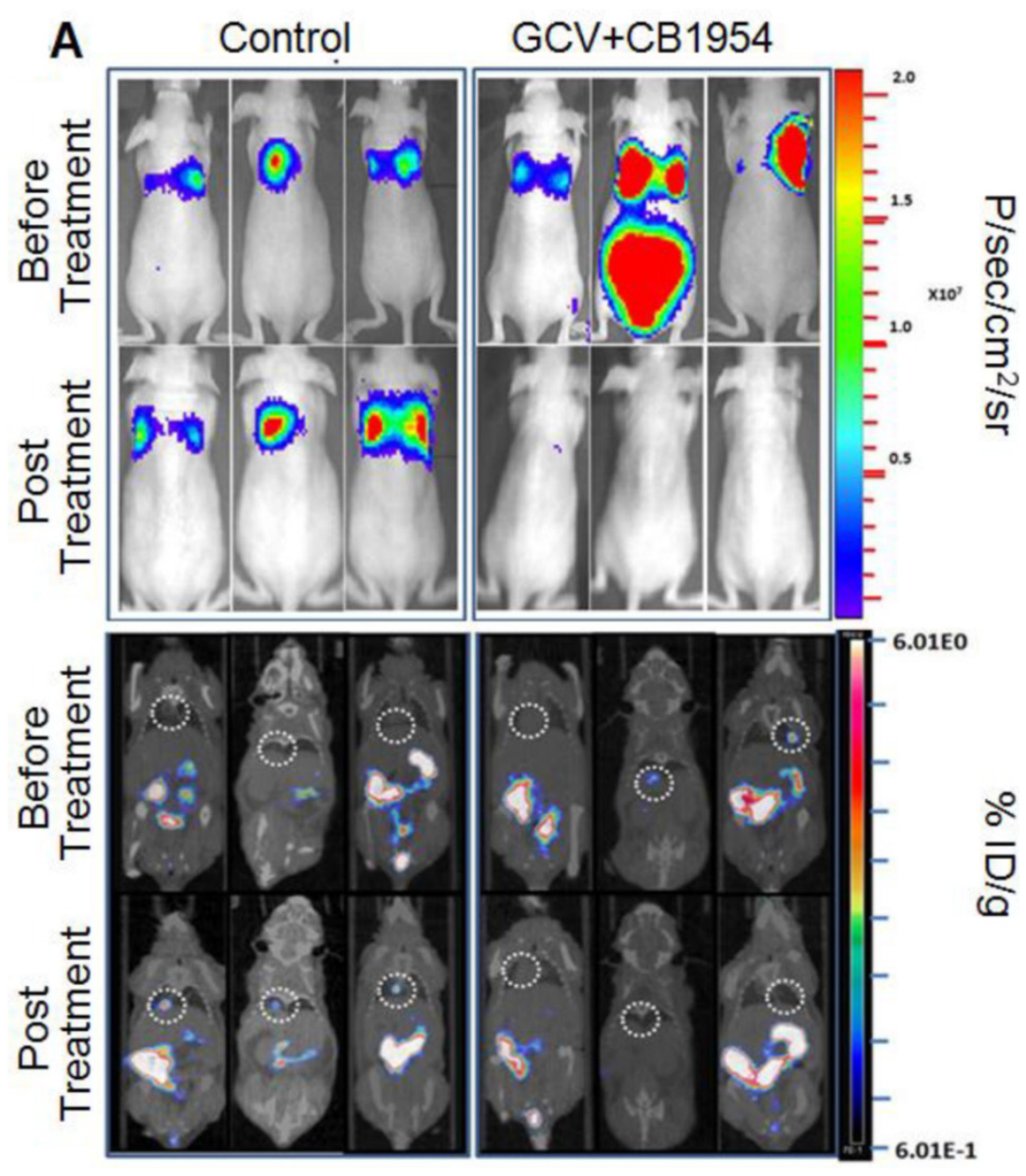

\section{B}
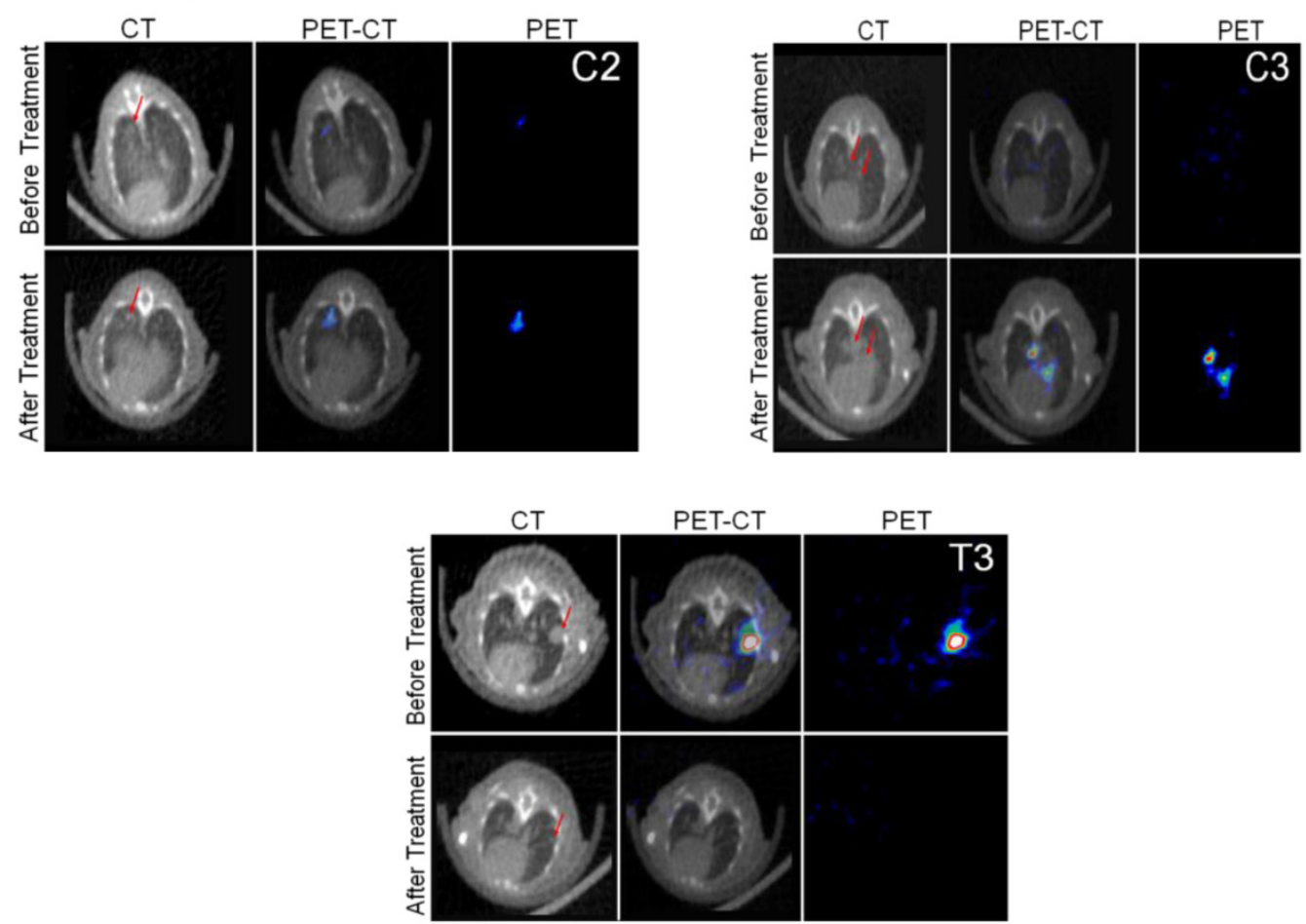

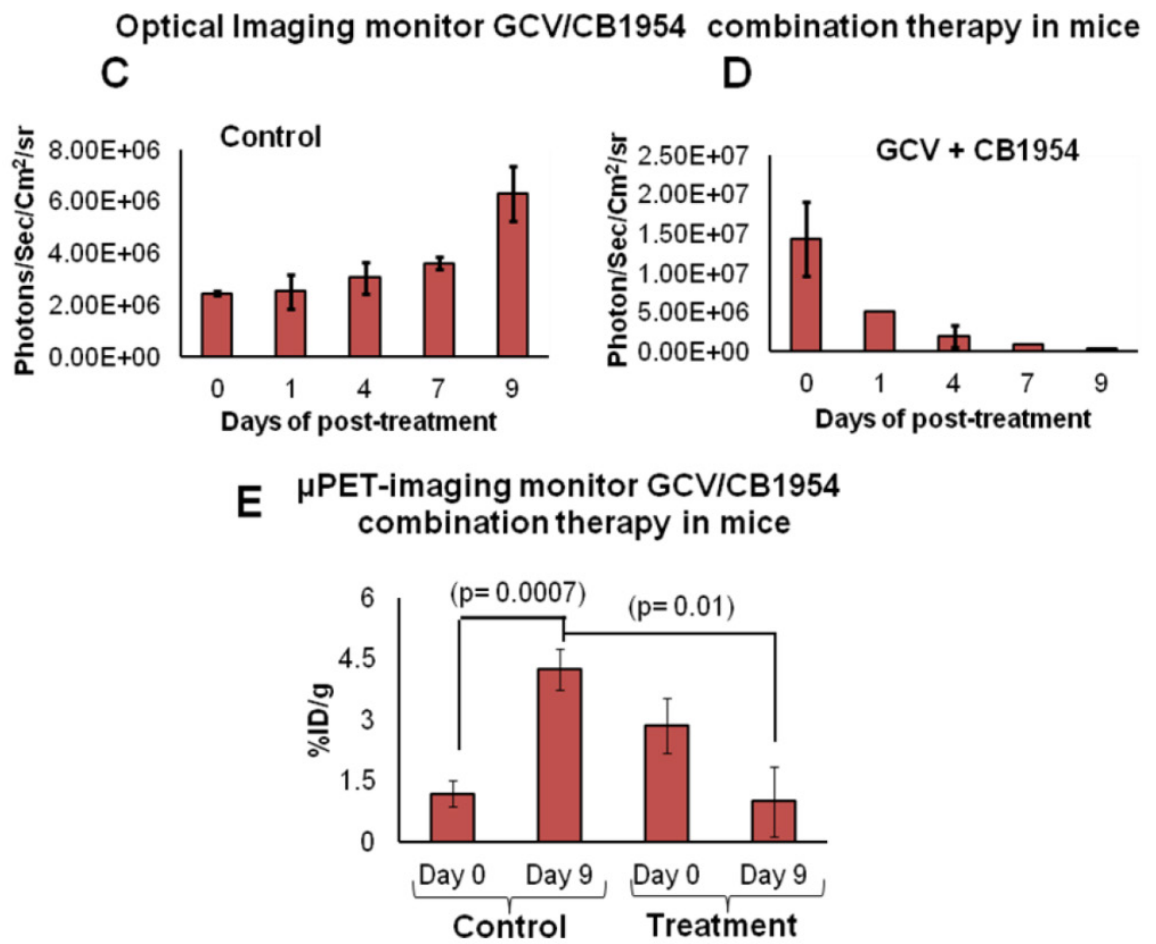

Figure 4. Therapeutic evaluation of GCV $(40 \mathrm{mg} / \mathrm{kg})+\mathrm{CB} / 954(40 \mathrm{mg} / \mathrm{kg})$ combination in MDA-MB-23I metastatic tumor stably expressing HSVI-sr39TK-NTR in mouse model by optical bioluminescence and $\mu$ PET/CT imaging. A. Upper panel shows the optical images captured with control nude mice group and animals treated with GCV + CBI954, Lower panel shows the I8F-FHBG $\mu$ PET/CT images acquired in vehicle treated animal group. B. PET, CT, and PET-CT fusion images in transverse position at the lung metastatic tumor plane of animal 2 and 3 of control group (C2 and C3), and animal 3 of treatment group (T3). C. Optical bioluminescence signal in control animal group measured over time. D. Optical bioluminescence signal measured in animal group treated with two doses of a combination of GCV and CBI954. E. $\mu$ PET/CT imaging signal (\%ID/g) measured in control and treatment group before and after two doses of combination therapy.

A

\section{Microscopic images of H\&E stained TK-NTR lung metastatic tumors treated with CB1954, Vehicle and CB1954 + GCV combination}

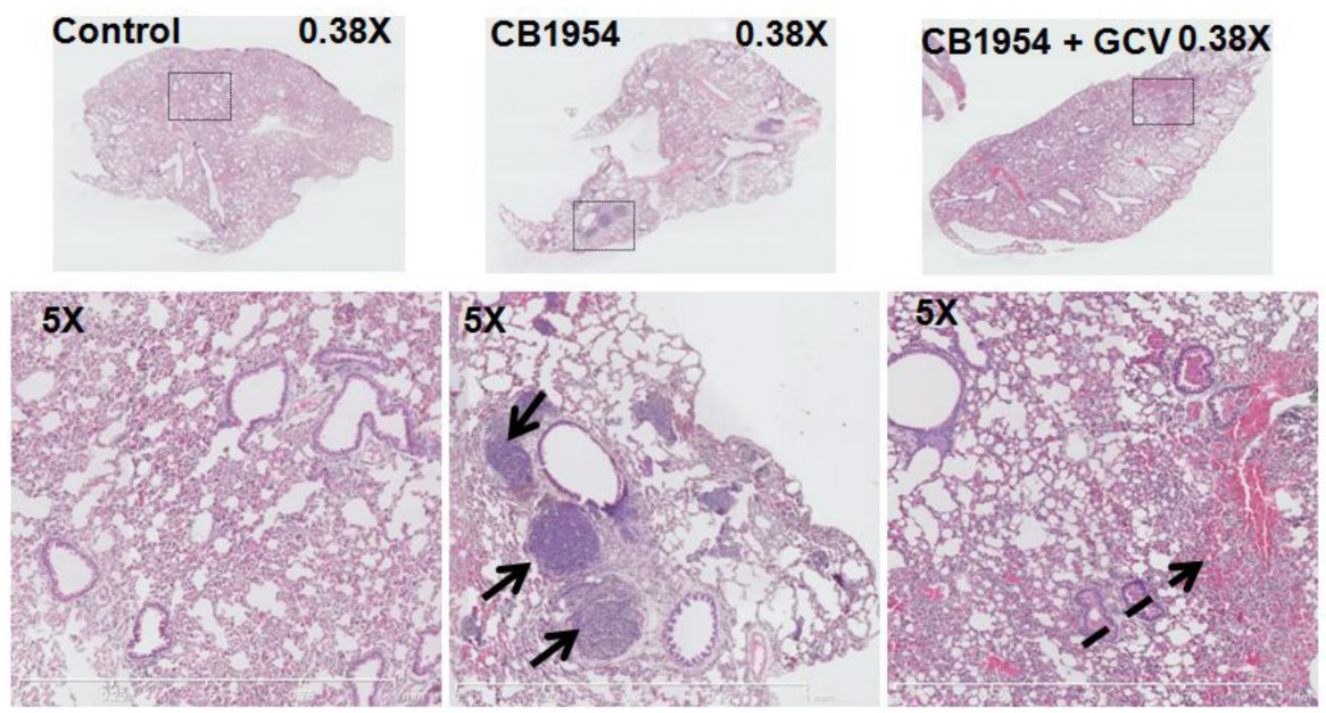


B

\section{Microscopic images of TUNEL stained TK-NTR lung metastatic tumors treated with CB1954, Vehicle and CB1954 + GCV combination}

\section{TUNEL Staining}

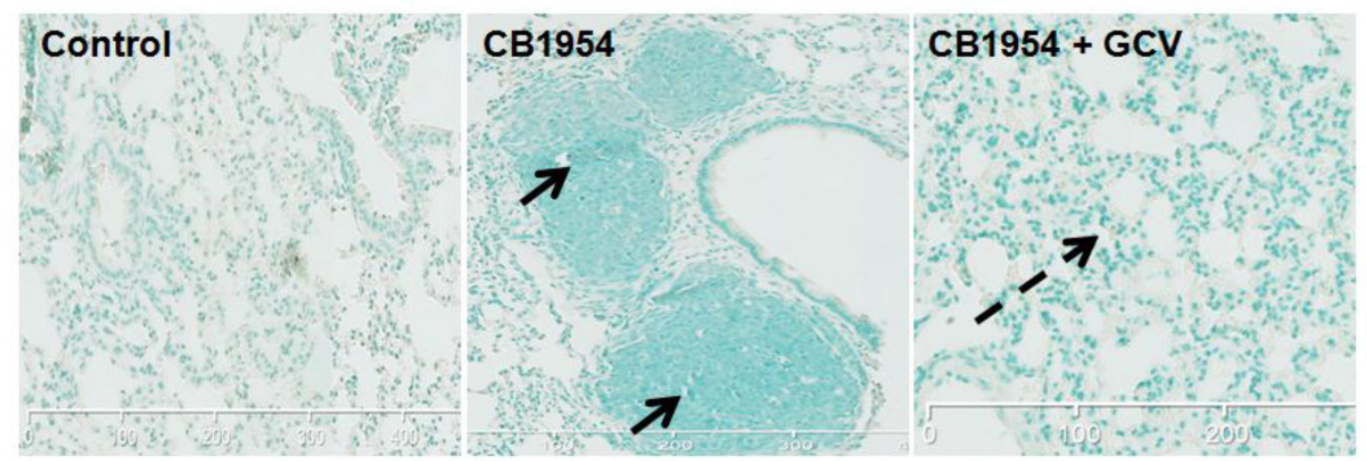

Figure 5. A, Microscopic images of H\&E stained HSVI-sr39TK-NTR metastatic tumors in lungs. Bottom panel shows the enlarged view of lung tissue portions of animals treated with GCV+CB 1954, vehicle and CBI 954 alone. B, Microscopic images of TUNEL stained HSVI-sr39TK-NTR metastatic tumor section of lungs. Microscopic images of HSVI-sr39TK-NTR metastatic tumor sections stained with TK-specific antibody and counter-stained with DAPI. Merged images show the intact tumor in control animal and cured tumor tissue in CBI954 + GCV treated animal.

Gene therapy with single enzyme/prodrug combinations targeting a single cellular mechanism need significant overexpression of the delivered therapeutic gene in order to achieve sufficient therapeutic response, a difficult feat in most gene delivery systems. Hence, to overcome this barrier, we recently developed a dual therapeutic reporter gene fusion that uses two different prodrugs targeting two cellular mechanisms to achieve effective therapy even with minimal expression of delivered transgenes. In addition, imaging therapeutic reporter genes offers additional information to correlate indirectly gene delivery, expression, and functional effects as a theranostic approach. GDEPT systems are potential treatment methods of metastatic cancers caused by various tumor types, if tumor targeting is established with viral vectors or nanoparticle-mediated delivery. As a first step towards developing an efficient enzyme prodrug combination, we identified such a combination that targets two different cellular mechanisms with significant bystander effect and that co-expressed in the nuclear compartment for efficient drug conversion and accessibility for DNA synthesis and intercalation. Further attempts are in progress to develop a targeted adeno-associated viral-gene delivery system in order to extend the use of this currently identified enzyme prodrug combination for metastatic tumor therapy in human. Attempts to investigate the therapeutic potency of GDEPT systems against devastating metastatic cancers are scarce. HSV1-sr39TK/GCV was investigated to treat lung-metastatic breast cancer, and lung-metastatic tumor burden diminished significantly after treating with GCV $(10 \mathrm{mg} / \mathrm{kg}$ body weight) consecutively for 7 days [28]. In addition, the combination of NTR and GM-CSF therapeutic strategy were found to be effective in treating prostate cancer (TRAMP model), which induces metastasis after 24 to 30 weeks of age in mice [13]. Recently, we explored the therapeutic potential of HSV1-sr39TK and E.coli NTR-mediated double suicide gene therapy and showed that HSV1-sr39TK-NTR fusion is more efficacious than either system alone. In addition, Yu et al. studied the treatment efficiency of HSV1-sr39TK and NTR combinations in an hTERT-driven adenovirus vector against subcutaneously implanted breast cancer cell line, ZR-75-30, basically derived from metastatic breast cancer [29]. Significant levels of tumor growth reduction were observed when GCV $(3.75 \mathrm{mg} / \mathrm{kg}$ ) was injected consecutively for 4 days and CB1954 $(80 \mathrm{mg} / \mathrm{kg})$ for 2 days [29]. As HSV1-TK-NTR fusion showed enhanced therapeutic potential, we intended to explore whether HSV1-sr39TK-NTR fusion was able to cure metastatic breast cancer in a mice model of lung-metastatic breast cancer implanted with a triple negative breast cancer cell line, MDA-MB-231 co-expressing HSV1-sr39TK-NTR and Fluc-EGFP fusions. Even though we used tail vein injected lung metastatic model in this study, it is not similar to real metastatic tumors appear from a primary tumor in humans. However, various previous studies have shown that the gene expression profile of metastatic tumors derived from orthotopically implanted primary tumors are not significantly different from the one created by tail vein implantation [30]. In addition, the drug delivery, pharmacokinetic properties of drugs, and their 
mode of actions in this tumor are not significantly different from lung metastatic nodules derived primary tumors, hence we used this simple model for this study. To monitor the therapeutic value of HSV1-sr39TK-NTR/GCV-CB1954, we employed in vivo optical imaging, and $\mu \mathrm{PET} / \mathrm{CT}$ imaging using $\left[{ }^{18} \mathrm{~F}\right]-\mathrm{FHBG}$, a radioactive thymidine kinase specific tracer, selectively taken by cells expressing HSV1-sr39TK [31]. We administered GCV and CB1954 combinations twice, with an interval of 5 days apart, after lung-metastatic tumor establishment. Significant reduction of Fluc signal was observed 9 days after two doses of drug treatment in the animal group treated with GCV and CB1954 combination when compared with the animal group treated with the same quantity of either GCV or CB1954 alone. HSV1-sr39TK/GCV in combination with GM-CSF and IL-2 proved to be an highly efficacious GDEPT system to treat lung-metastatic breast cancer [32]; however, it confers little bystander effect when compared with NTR/CB1954 and HSV1-TK-NTR/GCV+CB1954 GDEPT systems [20]. Therefore, HSV1-sr39TK-NTR fusion-based double-suicide gene therapy may be a promising therapeutic system in a clinical setting. Although further studies are needed, HSV1-sr39TK-NTR fusion in combination with GM-CSF and IL-2 may append further therapeutic potential to the HSV1-sr39TK-NTR double-suicide gene therapy system.

By achieving uniform expression of therapeutic genes and the use of optimal concentration of prodrugs in this study, we were able to achieve higher level of therapeutic index with the use of both GCV and CB1954 as combination. Even though previous studies have shown the efficiency of HSV1-TK/GCV system, most studies used cells heterogeneously express varying levels of the transduced therapeutic gene under a variety of expression cassettes. Jang et al reported that C6-TL cells expressing HSV1-TK was able to show $65 \%$ of cell death when treated with 10 $\mu \mathrm{M} \mathrm{GCV}$ in vitro in cell culture, while GCV dose of 50 $\mathrm{mg} / \mathrm{kg}$ body weight once daily for 7 days was able to reduce tumor volume in animals [33]. But in this study the tumors started growing again after the completion of GCV therapy. Similarly, HSV1-TK transduced by a Cre-LoxP based targeted lenti- viral system was able to achieve $87.23 \%$ of apoptosis in response to $20 \mu \mathrm{g} / \mathrm{ml}$ of GCV treatment for $96 \mathrm{~h}$ [34]. HSV1-TK/GCV therapy system was evaluated by another study to treat Epstein - Barr virus associated cancer. HSV1-TK (pVLTR-TK) expressed in EBV-LMP1 positive nasopharyngeal squamous carcinoma cells showed $20 \%$ apoptosis when treated cells with $200 \mu \mathrm{g} / \mathrm{ml}$ of GCV [35]. In contrast to these findings, the present study showed $23 \%$ of apoptosis in MDA-MB-231 cells expressing HSV1-TK in response to $1 \mu \mathrm{g} / \mathrm{ml}$ of GCV treatment for $72 \mathrm{~h}$ and $71.4 \%$ of apoptosis in HSV1-TK-NTR expressing MDA-MB-231 cells with $1 \mu \mathrm{g} / \mathrm{ml} \mathrm{GCV}+10 \mu \mathrm{M}$ CB1954 for $72 \mathrm{~h}$. These results clearly showed that HSV1-TK-NTR fusion induces high percentage of cytotoxicity with the use of low doses of dual prodrugs (GCV and CB1954).

In summary, we showed the enhanced therapeutic potentials of the HSV1-sr39TK and E.coli NTR-fused double-gene therapy system in a triple negative and metastatic breast cancer mouse model when compared with either the HSV1-sr39TK or NTR systems alone. Metastatic breast cancer was completely uprooted in 9 days after just two doses of GCV and CB1954 combined drug treatment; however, tumor recurrences need to be addressed. Furthermore, the TK-NTR fusion GDEPT system would be a promising gene therapy strategy provided that tumor targeting and selective delivery system can be achieved.

\section{Supplementary Material}

Additional File 1:

C3 - pre-treatment.

http://www.thno.org/v04p0460s1.avi

Additional File 2:

C3 - post-treatment.

http://www.thno.org/v04p0460s2.avi

Additional File 3:

T3 - pre-treatment.

http://www.thno.org/v04p0460s3.avi

Additional File 4:

T3 - pre-treatment.

http://www.thno.org/v04p0460s4.avi

\section{Acknowledgements}

We thank Department of Radiology, Stanford University School of Medicine, and NIH-NCI RO1CA161091 (R. Paulmurugan) for funding support and the Canary Center at Stanford, Department of Radiology for facility and resources. We also thank $\mathrm{SCi}^{3}$ small animal imaging service center, Stanford University School of Medicine for providing imaging facilities and data analysis. We gratefully acknowledge the constant support and encouragement rendered by Dr. Sanjiv S Gambhir, Chair, Department of Radiology, and Stanford University School of Medicine.

\section{Competing Interests}

The authors have declared that no competing interest exists. 


\section{References}

1. Tseng LM, Hsu NC, Chen SC, Lu YS, Lin CH, Chang DY, et al. Distant metastasis in triple-negative breast cancer. Neoplasma. 2013; 60: 290-4.

2. Mailly L, Leboeuf C, Tiberghien P, Baumert T, Robinet E. Genetically engineered T-cells expressing a ganciclovir-sensitive HSV-tk suicide gene for the prevention of GvHD. Curr Opin Investig Drugs. 2010; 11: 559-70.

3. Morris JC, Ramsey WJ, Wildner O, Muslow HA, Aguilar-Cordova E, Blaese RM. A phase I study of intralesional administration of an adenovirus vector expressing the HSV-1 thymidine kinase gene (AdV.RSV-TK) in combination with escalating doses of ganciclovir in patients with cutaneous metastatic malignant melanoma. Hum Gene Ther. 2000; 11: 487-503.

4. Patel P, Young JG, Mautner V, Ashdown D, Bonney S, Pineda RG, et al. A phase I/II clinical trial in localized prostate cancer of an adenovirus expressing nitroreductase with CB1954 [correction of CB1984]. Mol Ther. 2009; 17: 1292-9.

5. Searle PF, Chen MJ, Hu L, Race PR, Lovering AL, Grove JI, et al Nitroreductase: a prodrug-activating enzyme for cancer gene therapy. Clin Exp Pharmacol Physiol. 2004; 31: 811-6.

6. Knox RJ. Gene-directed enzyme prodrug therapy (GDEPT)--recognizing the present limitations of gene therapy for the treatment of cancer. Curr Opin Investig Drugs. 2001; 2: 835-8.

7. Field AK, Davies ME, DeWitt C, Perry HC, Liou R, Germershausen J, et al. 9-([2-hydroxy-1-(hydroxymethyl)ethoxy]methyl)guanine: a selective inhibitor of herpes group virus replication. Proc Natl Acad Sci U S A. 1983; 80: 4139-43.

8. Bridgewater JA, Knox RJ, Pitts JD, Collins MK, Springer CJ. The bystander effect of the nitroreductase/CB1954 enzyme/prodrug system is due to a cell-permeable metabolite. Hum Gene Ther. 1997; 8: 709-17.

9. Kuriyama S, Masui K, Sakamoto T, Nakatani T, Kikukawa M, Tsujinoue H, et al. Bystander effect caused by cytosine deaminase gene and 5-fluorocytosine in vitro is substantially mediated by generated 5 -fluorouracil. Anticancer Res. 1998; 18: 3399-406.

10. Nicholas TW, Read SB, Burrows FJ, Kruse CA. Suicide gene therapy with Herpes simplex virus thymidine kinase and ganciclovir is enhanced with connexins to improve gap junctions and bystander effects. Histol Histopathol. 2003; 18: 495-507.

11. McNeish IA, Tenev T, Bell S, Marani M, Vassaux G, Lemoine N. Herpes simplex virus thymidine kinase/ganciclovir-induced cell death is enhanced by co-expression of caspase-3 in ovarian carcinoma cells. Cancer Gene Ther. 2001; 8: 308-19.

12. Jones RK, Pope IM, Kinsella AR, Watson AJ, Christmas SE. Combined suicide and granulocyte-macrophage colony-stimulating factor gene therapy induces complete tumor regression and generates antitumor immunity. Cancer Gene Ther. 2000; 7: 1519-28.

13. Young JG, Green NK, Mautner V, Searle PF, Young LS, James ND. Combining gene and immunotherapy for prostate cancer. Prostate Cancer Prostatic Dis. 2008; 11: 187-93.

14. Chung-Faye GA, Chen MJ, Green NK, Burton A, Anderson D, Mautner V, et al. In vivo gene therapy for colon cancer using adenovirus-mediated, transfer of the fusion gene cytosine deaminase and uracil phosphoribosyltransferase. Gene Ther. 2001; 8: 1547-54

15. Ramnaraine M, Pan W, Goblirsch $M$, Lynch C, Lewis V, Orchard P, et al. Direct and bystander killing of sarcomas by novel cytosine deaminase fusion gene. Cancer Res. 2003; 63: 6847-54.

16. Freytag SO, Rogulski KR, Paielli DL, Gilbert JD, Kim JH. A novel three-pronged approach to kill cancer cells selectively: concomitant viral, double suicide gene, and radiotherapy. Hum Gene Ther. 1998; 9: 1323-33.

17. Rogulski KR, Kim JH, Kim SH, Freytag SO. Glioma cells transduced with an Escherichia coli CD/HSV-1 TK fusion gene exhibit enhanced metabolic suicide and radiosensitivity. Hum Gene Ther. 1997; 8: 73-85.

18. Barton KN, Paielli D, Zhang $\mathrm{Y}$, Koul S, Brown SL, Lu M, et al. Second-generation replication-competent oncolytic adenovirus armed with improved suicide genes and ADP gene demonstrates greater efficacy without increased toxicity. Mol Ther. 2006; 13: 347-56.

19. Bhaumik S, Sekar TV, Depuy J, Klimash J, Paulmurugan R. Noninvasive optical imaging of nitroreductase gene-directed enzyme prodrug therapy system in living animals. Gene Ther. 2012; 19: 295-302.

20. Sekar TV, Foygel K, Willmann JK, Paulmurugan R. Dual-therapeutic reporter genes fusion for enhanced cancer gene therapy and imaging. Gene Ther. 2013; 20: 529-37.

21. Yaghoubi SS, Jensen MC, Satyamurthy N, Budhiraja S, Paik D, Czernin J, et al. Noninvasive detection of therapeutic cytolytic T cells with 18F-FHBG PET in a patient with glioma. Nat Clin Pract Oncol. 2009; 6: 53-8.

22. Soret M, Bacharach SL, Buvat I. Partial-volume effect in PET tumor imaging. J Nucl Med. 2007; 48: 932-45.

23. Ray P, Tsien R, Gambhir SS. Construction and validation of improved triple fusion reporter gene vectors for molecular imaging of living subjects. Cancer Res. 2007; 67: 3085-93.

24. Shu CJ, Radu CG, Shelly SM, Vo DD, Prins R, Ribas A, et al. Quantitative PET reporter gene imaging of CD8+ T cells specific for a melanoma-expressed self-antigen. Int Immunol. 2009; 21: 155-65.

25. Barinoff J, Hils R, Bender A, Gross J, Kurz C, Tauchert S, et al. Clinicopathological differences between breast cancer in patients with primary metastatic disease and those without: a multicentre study. Eur J Cancer. 2013; 49: 305-11.
26. Marquette C, Nabell L. Chemotherapy-resistant metastatic breast cancer. Curr Treat Options Oncol. 2012; 13: 263-75.

27. Andre F, Zielinski CC. Optimal strategies for the treatment of metastatic triple-negative breast cancer with currently approved agents. Ann Oncol. 2012; 23 Suppl 6: vi46-51.

28. Deng WP, Wu CC, Lee CC, Yang WK, Wang HE, Liu RS, et al. Serial in vivo imaging of the lung metastases model and gene therapy using HSV1-tk and ganciclovir. J Nucl Med. 2006; 47: 877-84

29. Yu B, Zhang Y, Zhan Y, Zha X, Wu Y, Zhang X, et al. Co-expression of herpes simplex virus thymidine kinase and Escherichia coli nitroreductase by an hTERT-driven adenovirus vector in breast cancer cells results in additive anti-tumor effects. Oncol Rep. 2011; 26: 255-64.

30. Rashid OM, Nagahashi M, Ramachandran S, Dumur CI, Schaum JC, Yamada $\mathrm{A}$, et al. Is tail vein injection a relevant breast cancer lung metastasis model? J Thorac Dis. 2013; 5: 385-92.

31. Tjuvajev JG, Doubrovin M, Akhurst T, Cai S, Balatoni J, Alauddin MM, et al. Comparison of radiolabeled nucleoside probes (FIAU, FHBG, and FHPG) for PET imaging of HSV1-tk gene expression. J Nucl Med. 2002; 43: 1072-83.

32. Majumdar AS, Zolotorev A, Samuel S, Tran K, Vertin B, Hall-Meier M, et al. Efficacy of herpes simplex virus thymidine kinase in combination with cytokine gene therapy in an experimental metastatic breast cancer model. Cancer Gene Ther. 2000; 7: 1086-99.

33. Jang SJ, Kang JH, Kim KI, Lee TS, Lee YJ, Lee KC, et al. Application of bioluminescence imaging to therapeutic intervention of herpes simplex virus type I - Thymidine kinase/ganciclovir in glioma. Cancer Lett. 2010; 297: 84-90.

34. Jiang YX, Lu Y, Liu TJ, Yang J, Chen Y, Fang YW. Using HSV-TK/GCV suicide gene therapy to inhibit lens epithelial cell proliferation for treatment of posterior capsular opacification. Mol Vis. 2011; 17: 291-9.

35. Lifang Y, Min T, Midan A, Ya C. HSV-tk/GCV gene therapy mediated by EBV-LMP1 for EBV-associated cancer. J Exp Clin Cancer Res. 2008; 27: 42. 